\title{
Calix[n]phenothiazines: Optoelectronic and Structural Properties and Host-Guest Chemistry
}

\author{
Maximilian Schmidt ${ }^{a}$ \\ Mathias Hermann ${ }^{a}$ \\ Fabian Otteny ${ }^{a}$ \\ Birgit Esser*a,b,c \\ ${ }^{a}$ Institute for Organic Chemistry, University of \\ Freiburg, Albertstr. 21, 79104 Freiburg. \\ Germany \\ ${ }^{\mathrm{b}}$ Freiburg Materials Research Center, University \\ of Freiburg, Stefan-Meier-Str. 21, 79104 \\ Freiburg, Germany \\ cCluster of Excellence livMatS @ FIT - Freiburg \\ Center for Interactive Materials and \\ Bioinspired Technologies, University of \\ Freiburg, Georges-Köhler-Allee 105, 79110 \\ Freiburg, Germany \\ besser@oc.uni-freiburg.de
}
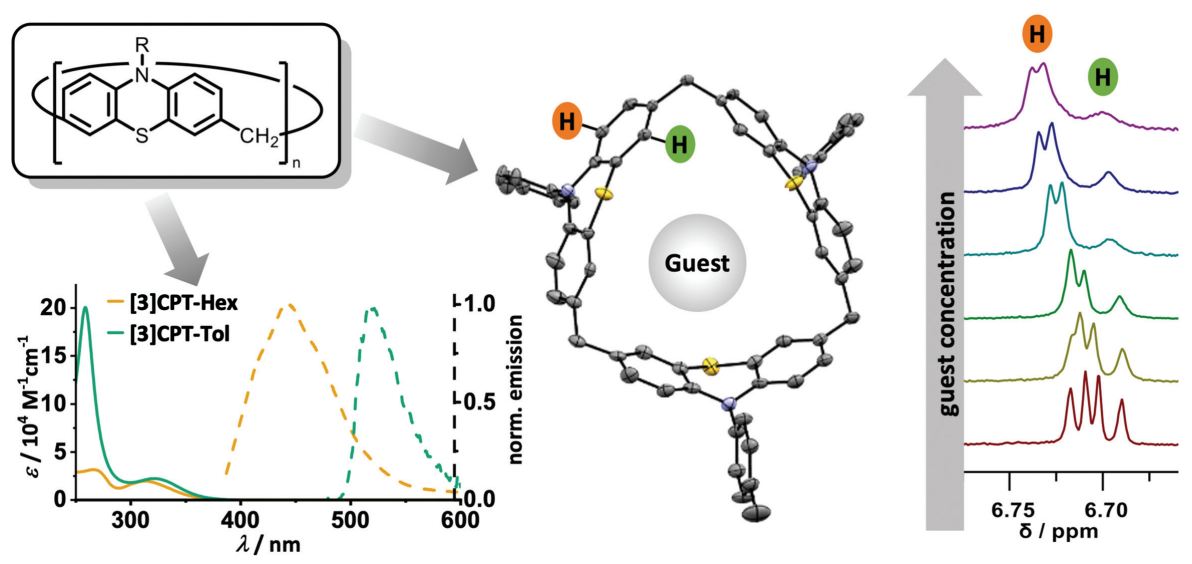

Received: 20.05.2020

Accepted after revision: 8.06.2020

DOI: 10.1055/s-0040-1714295; Art ID: om-20-0018sc

License terms: (c)

(c) 2020. The Author(s). This is an open access article published by Thieme under the terms of the Creative Commons Attribution-NonDerivative-NonCommercial-License, permitting copying and reproduction so long as the original work is given appropriate credit. Contents may not be used for commercial purposes, or adapted, remixed, transformed or built upon. (https://creativecommons.org/licenses/by-nc-nd/4.0/).

Abstract Calixarenes are of interest as receptors for ions and small molecules and as organic materials. Exchanging the arene units through heteroaromatics allows changing their optoelectronic and host-guest properties. We herein present calix $[n]$ phenothiazines $(n=3,4)$ as novel macrocycles, accessible in two-step syntheses. The phenothiazine units show reversible redox events and emissive properties, and $N$-hexylsubstituted calix[3]phenothiazine binds to both ammonium ions and a bisimidazole as neutral guests.

Key words Calixarenes, macrocycles, phenothiazine, host-guest chemistry, conformational flexibility

\section{Introduction}

Calix $[n]$ arenes $^{1,2}$ as "chalice-like" macrocycles have found widespread interest and applications, most prominently as receptors for ions and small molecules, but also in organic materials. ${ }^{3}$ Calix[4] ]arenes are the most common, consisting of four 4-substituted phenols, methylene-bridged in the 2,6positions. Incorporating other aromatics than phenol will alter the optoelectronic and host-guest properties of the calixarenes. Examples are calix[4]pyrroles, ${ }^{4}$ calix[ $\left.n\right]$ furanes $(n=5-$ $8),{ }^{5,6}$ calix [4] thiophenes, ${ }^{7}$ calix $[n]$ triazoles $(n=4-6),{ }^{8}$ calix $[n]$ imidazolium salts $(n=4,5),{ }^{9}$ calix $\left.n\right]$ indoles $(n=3,4),{ }^{10-12}$ and the recently reported calix $[n]$ carbazoles $(n=3,4) .{ }^{13,14}$ Phenothiazine has long been of interest to chemists ${ }^{15,16}$ due to its pharmacological and biological activity ${ }^{15-18}$ and its use in dye chemistry, ${ }^{19-21}$ among others. Phenothiazines are fluorescent and feature a reversible oxidation process, which makes them attractive for applications in organic electronics ${ }^{22-24}$ and in batteries. ${ }^{25-28}$ They are also strong excited-state reductants and have been used in photoredox catalysis. ${ }^{29-31}$ Incorporating phenothiazines into calixarene structures will therefore endow the above-mentioned properties to the macrocycles. We herein report on the synthesis and optoelectronic and structural properties of calix[ $n]$ phenothiazines [n]CPT-Hex $(n=3,4)$ and [3]CPT-Tol (Scheme 1$)$ as well as the host-guest chemistry of the hexyl derivative. To the best of our knowledge, calix $[n]$ phenothiazines have not been reported in the literature before.

\section{Results and Discussion}

Calix $[n]$ phenothiazines [n]CPT-Hex $(n=3,4)$ and [3]CPT-Tol were accessed in a facile two-step synthesis (Scheme 1). Alkylation of phenothiazine (1) with 1-bromohexane furnished $N$-hexylphenothiazine (2) in excellent yield. This was then reacted with paraformaldehyde under acidic conditions and $5 \mathrm{mM}$ dilution to yield calix[ $n$ ]phenothiazines [3]CPT-Hex and [4]CPT-Hex in 15\% and $4 \%$ yield, respectively, after separation by semipreparative gel permeation chromatography. Similarly, $\mathrm{N}$-(paratolyl)phenothiazine (3), synthesized by Buchwald-Hartwig coupling of phenothiazine (1) with para-bromotoluene, was cyclized with paraformaldehyde under the same acidic conditions and afforded [3]CPT-Tol in a good yield of 30\% (Scheme 1). Experiments to increase the yields of the 


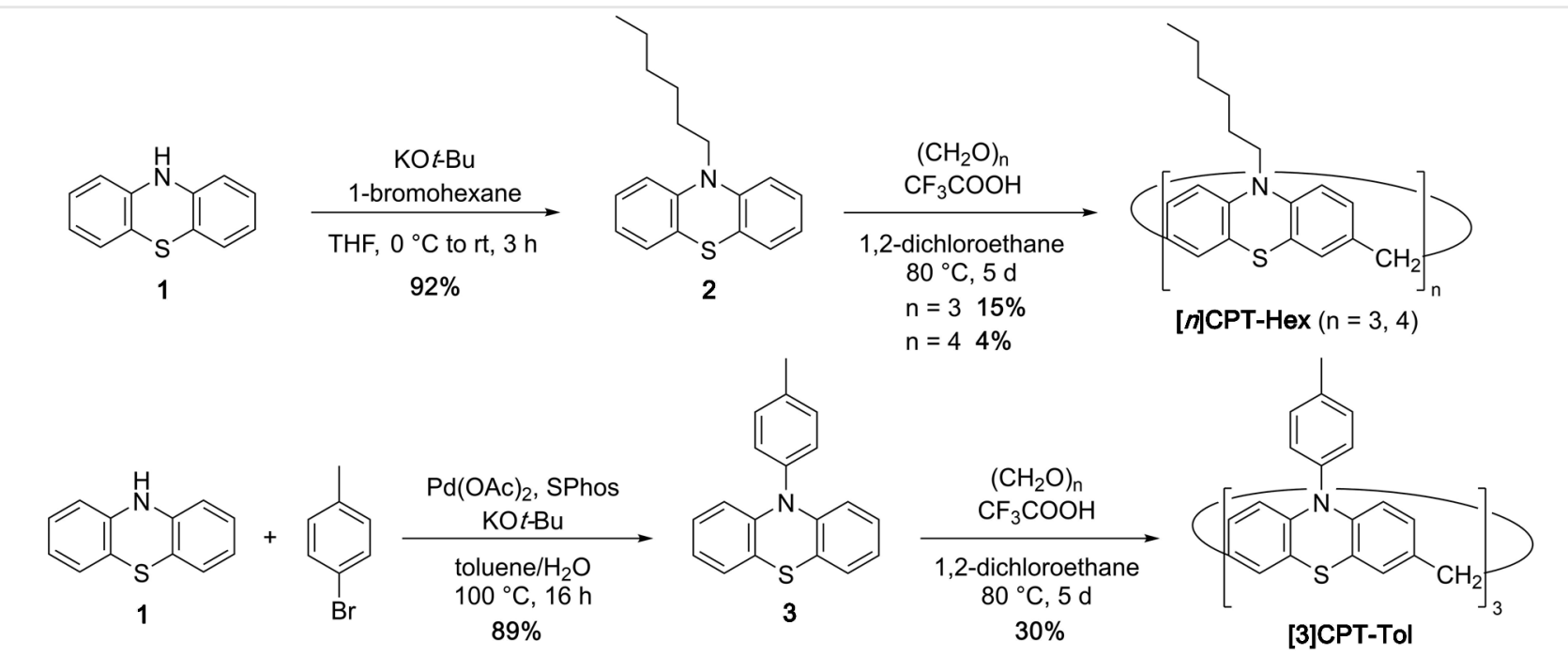

Scheme 1 Syntheses of calix[n]phenothiazines [n]CPT-Hex $(n=3,4)$ and [3]CPT-Tol.

cyclization reactions by adding tetraethylammonium bromide as a template molecule were not successful [see Supporting Information (SI) for more details].

The NMR spectra confirmed the high symmetry of the formed calix[ $n]$ phenothiazines (Figure 1). Each spectrum displayed only one set of signals for the phenothiazine units and the bridging $\mathrm{CH}_{2}$-groups. Regarding their structures, for the calix[3]phenothiazines two conformers are possible with all phenothiazines oriented the same way (AAA) or one rotated the other way (AAB). Density-functional theory (DFT) calculations on the PW6B95-D3/def2-QZVP level of theory showed the $\mathrm{AAB}$ conformation to be slightly more stable by $1.2 \mathrm{kcal} \mathrm{mol}^{-1}$ for [3]CPT-Me (hexyl groups in [3]CPT-Hex were replaced by methyl) and $1.3 \mathrm{kcal} \mathrm{mol}^{-1}$ for [3]CPT-Tol. NMR spectra indicated a fast conformational isomerism and no change in signals for [3]CPT-Hex and [3]CPT-Tol in the temperature range of 233-300 $\mathrm{K}$ (see Supporting Information for VT-NMR spectra).

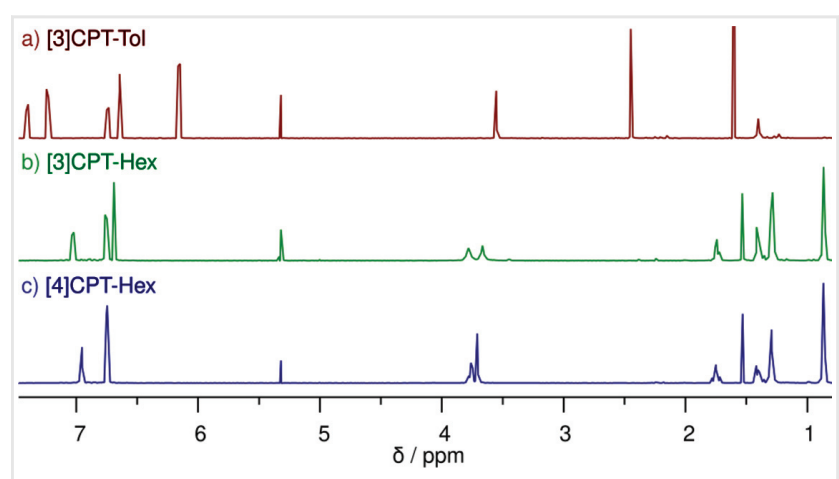

Figure $1{ }^{1} \mathrm{H}$ NMR spectra of calix[n]phenothiazines [3]CPT-Tol (a), [3]CPT-Hex (b), and [4]CPT-Hex (c) in $\mathrm{CD}_{2} \mathrm{Cl}_{2}$ (500 MHz).
For the calix[4]phenothiazine [4]CPT-Hex, four conformations (AAAA, $A A A B, A A B B$, and $A B A B$ ) are possible (see Supporting Information for structures) as for the commonly known calix[4]arenes. ${ }^{3}$ Calculations on the PW6B95-D3/def2-QZVP level of theory on the methyl derivatives [4]CPT-Me of all four conformers showed AAAA to be most stable followed by AAAB $\left(+1.2 \mathrm{kcal} \mathrm{mol}^{-1}\right), \mathrm{ABAB}\left(+2.3 \mathrm{kcal} \mathrm{mol}^{-1}\right)$, and AABB $\left(+3.4 \mathrm{kcal} \mathrm{mol}^{-1}\right)$. Also in this case, the high symmetry of the NMR spectra indicated a fast conformational isomerism.

The molecular structure of [3]CPT-Tol in the solid state was resolved by X-ray diffraction. Single crystals were grown by layering a toluene solution with methanol. For comparison, the structure of $\mathbf{3}$ was also determined by X-ray diffraction (see Supporting Information for details). [3]CPTTol crystallized in the AAB conformation (Figure 2). The structure had no symmetry elements, resulting in three different butterfly angles for the phenothiazine units.

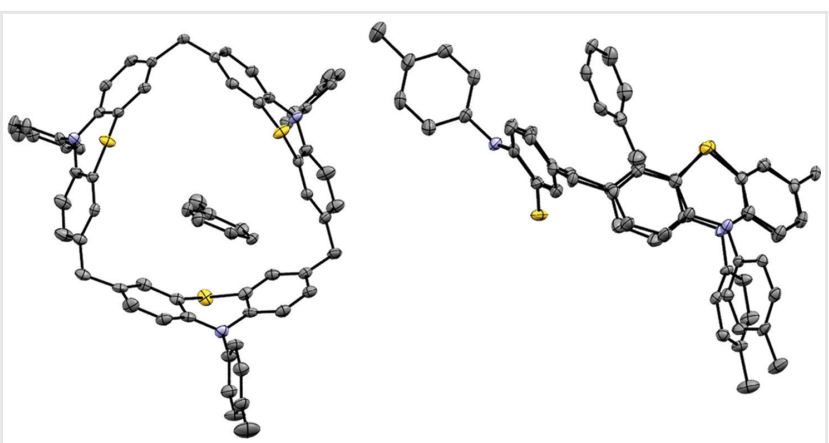

Figure 2 Molecular structure of [3]CPT-Tol in the solid state (displacement ellipsoids are shown at the $50 \%$ probability level; hydrogen atoms are omitted for clarity). 
The butterfly angles amounted to $159.3^{\circ}$ and $153.4^{\circ}$ for the "A"-phenothiazines and $142.8^{\circ}$ for the "B"-phenothiazine, similar to that of $\mathrm{N}$-(para-tolyl)phenothiazine (3) of $151.1^{\circ}$. The space in the cavity (distances between the phenothiazine subunits) amounts to 7.44-7.87 $\AA$ and can accommodate a toluene solvent molecule, which co-crystallized (Figure 2).

The cyclic voltammograms of the calix[ $n]$ phenothiazines confirmed reversible redox processes due to the phenothiazine units (Figure 3). In the smaller calix[3]phenothiazines, the first oxidation was split into two processes due to the close proximity of the phenothiazine units at $E_{1 / 2}=0.25$ and $0.37 \mathrm{~V}$ for [3]CPT-Tol and at $E_{1 / 2}=0.15$ and $0.29 \mathrm{~V}$ for [3]CPT-Hex (all vs. $\mathrm{Fc} / \mathrm{Fc}^{+}$). In acyclic $N$-(para-tolyl)phenothiazine (3) and $N$-methylphenothiazine, these events are visible at $E_{1 / 2}=0.25 \mathrm{~V}$ and $0.32 \mathrm{~V}$, respectively, vs. Fc/Fc ${ }^{+}$ (see Supporting Information). A split of the first oxidation has also been reported for linear phenothiazine oligomers ${ }^{32}$ and cyclic phenothiazinophanes depending on the linking unit. $^{33,34}$ In the larger [4]CPT-Hex, no split of the first oxidation wave was observed. The second oxidations of the phenothiazine units to dications occurred at $E_{1 / 2}=0.99 \mathrm{~V}$ (reversible), $E_{1 / 2}=0.97 \mathrm{~V}$ (quasi-reversible), and $0.98 \mathrm{~V}$ (anodic peak potential) for [3]CPT-Tol, [3]CPT-Hex, and [4]CPT-Hex, respectively.

DFT calculations of the calix[3]phenothiazines showed the relevant orbitals to be located on two respective ones of

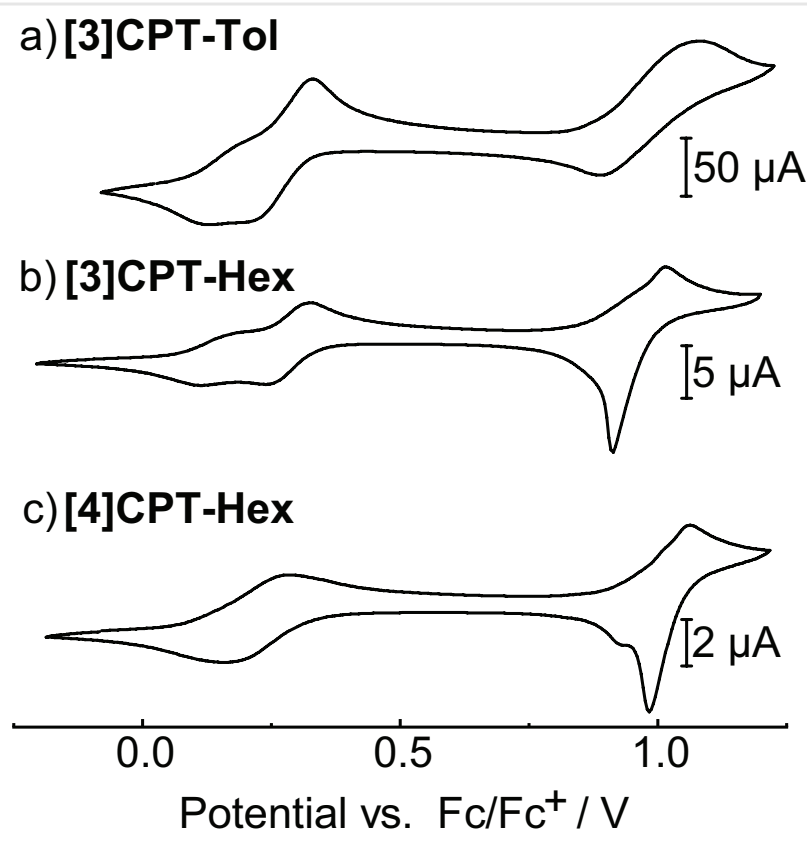

Figure 3 Cyclic voltammograms of calix[n]phenothiazines (in $\mathrm{CH}_{2} \mathrm{Cl}_{2}$, $0.1 \mathrm{M} \mathrm{n}$-Bu $\mathrm{NPF}_{6}$, scan rate $\left.0.1 \mathrm{~V} \mathrm{~s}^{-1}\right)$. (a) [3]CPT-Tol $(0.33 \mathrm{mM}$, glassy carbon electrode); (b) [3]CPT-Hex (0.33 mM, Pt electrode); and (c) [4]CPT-Hex (0.25 mM, Pt electrode).

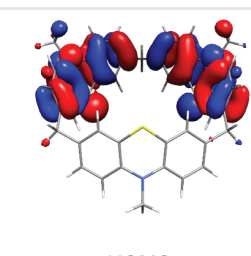

HOMO

$E=-5.02 \mathrm{eV}$ for [3]CPT-Me $E=-4.85 \mathrm{eV}$ for [3]CPT-Tol

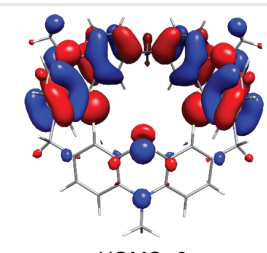

HOMO-2

$-5.09 \mathrm{eV}$ for [3]CPT-Me $-4.93 \mathrm{eV}$ for [3]CPT-Tol
Figure 4 Selected calculated orbitals for [3]CPT-Me with energies for orbitals of [3]CPT-Me and [3]CPT-Tol (B3LYP-D3/def2-TZVP) in the AAB conformation.

the phenothiazine units (shown for [3]CPT-Me in Figure 4, for [3]CPT-Tol the same distribution was obtained). HOMO, HOMO-1, and HOMO-2 lie close in energy, which explains the appearance of several redox waves in the CVs.

The absorption and emission properties of the calix $n]$ phenothiazines strongly depended on the $N$-substituent on the phenothiazines (Figure 5). For [3]- and [4]CPT-Hex, the absorption maxima were found to be at 266 and $315 \mathrm{~nm}$ and 260 and $312 \mathrm{~nm}$, respectively, while emission occurred with maxima at 445 and $454 \mathrm{~nm}$, respectively. In addition, [4]CPT-Hex showed a shoulder peak at $532 \mathrm{~nm}$. For [3]CPT-Tol, on the other hand, the absorption maxima were bathochromically shifted to 259 and $325 \mathrm{~nm}$ and occurred with a higher molar attenuation coefficient of log $\varepsilon=4$.3. The emission of [3]CPT-Tol was significantly redshifted to a maximum at $518 \mathrm{~nm}$. This corresponds to a large Stokes shift of $1.67 \mathrm{eV}$. This is surprising in comparison to $N$-(para-tolyl)phenothiazine (3), where absorption occurred with similar maxima of 258 and $321 \mathrm{~nm}$, while the emission maximum was at a much shorter wavelength of $448 \mathrm{~nm} .{ }^{35}$ For $N$-arylphenothiazines, emissions around or above $500 \mathrm{~nm}$ and such large Stokes shifts were only observed with electron-withdrawing substituents at the aryl group $\left(\mathrm{CN}\right.$ or $\left.\mathrm{CF}_{3}\right),{ }^{35}$ imparting a donor-acceptor character to the molecule. The origin of this bathochromic shift in [3]CPT-Tol is unclear.

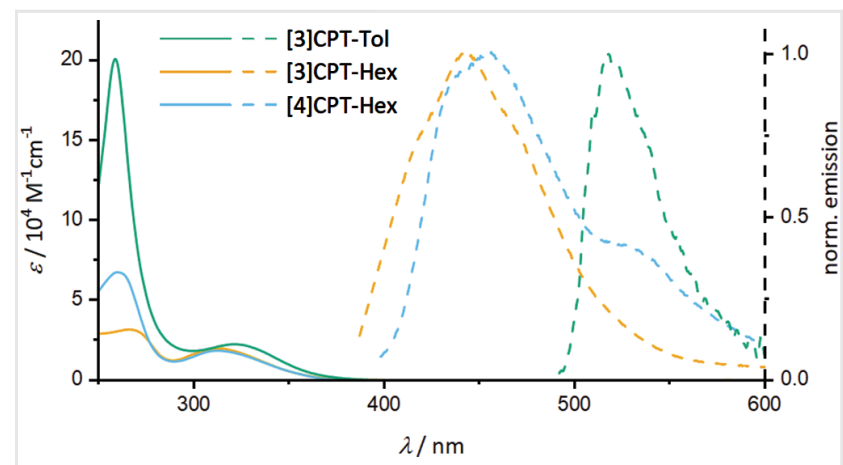

Figure 5 Absorption (solid lines) and emission spectra (dashed lines) of calix[n]phenothiazines in $\mathrm{CH}_{2} \mathrm{Cl}_{2}$. 


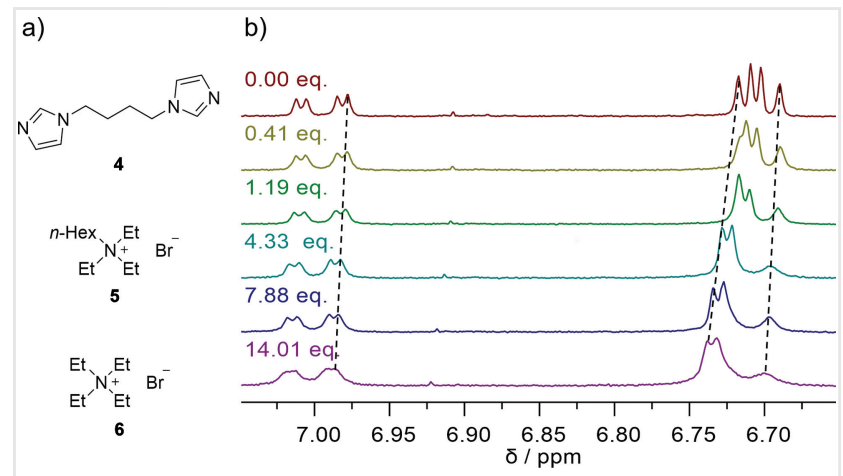

Figure 6 (a) Structures of guest molecules used in host-guest studies with [3]CPT-Hex. (b) Selected region of ${ }^{1} \mathrm{H}$ NMR spectra during titration of [3]CPT-Hex (2 mM) with $\mathbf{6}$ (added eq. of $\mathbf{6}$ from top to bottom: 0, $0.41,1.19,4.33,7.88,14.01$, solvent $\mathrm{CDCl}_{3}, 300 \mathrm{MHz}, 300 \mathrm{~K}$ ).

Finally, we performed host-guest studies of [3]CPT-Hex with different guests. For comparison with the recently reported calix[3]carbazole, ${ }^{13}$ we chose the imidazole derivative $\mathbf{4}$ as a neutral guest, which shows high binding constants (up to $10^{4} \mathrm{M}^{-1}$ ) towards pillar[5]arenes, ${ }^{36}$ as well as tetraalkylammonium cations, namely $\mathbf{5}$ and $\mathbf{6}$ (Figure 6a). NMR titration experiments ${ }^{37}$ of [3]CPT-Hex solutions with these guest molecules showed a shift in the phenothiazine ${ }^{1} \mathrm{H}$ NMR resonances with increasing guest concentrations (see Figure 6b, spectra for other titrations can be found in Supporting Information).

The fact that only one set of signals was visible indicated a fast exchange between free and complexed species. To obtain binding constants, we used a 1:1 binding model ${ }^{38-40}$ and an online tool provided by Thordarson and coworkers. ${ }^{37,41}$ The resulting binding constants were $K=50 \pm 3,91 \pm 4$, and $128 \pm 9 \mathrm{M}^{-1}$ for the complex formation between [3]CPT-Hex and 4, 5, and 6, respectively. For the ammonium cations $\mathbf{5}$ and $\mathbf{6}$, the binding constants are larger than that reported for calix[3]carbazole ${ }^{13}$ with the tetraethylammonium cation (up to $66.8 \mathrm{M}^{-1}$ ).

\section{Conclusions}

We herein presented three calix[ $n]$ phenothiazines as novel macrocycles. These calixarene derivatives showed reversible redox events and emissive properties due to the presence of the phenothiazine units. The structures are flexible at room temperature, allowing for fast conformational changes. The calix[3]phenothiazines can bind both cations and neutral guest molecules with binding constants to ammonium ions of up to $128 \mathrm{M}^{-1}$. Due to their facile two-step synthesis, these novel macrocycles could find widespread interest as receptors or as organic materials.

\section{Funding Information}

This study was funded by the German Research Foundation (ES 361/2-1, INST 40/467-1 FUGG).

\section{Acknowledgment}

We thank Dr. D. Kratzert for X-ray structure solution of $\mathbf{3}$. Generous support by the German Research Foundation and the state of Baden-Württemberg through bwHPC is gratefully acknowledged.

\section{Supporting Information}

Supporting information for this article is available online at http://doi.org/10.1055/s-0040-1714295.

\section{References and Notes}

Experimental procedures and characterization data: Details on materials and methods as well as synthetic procedures for compounds not mentioned in the following can be found in the SI.

Syntheses of [3]CPT-Hex and [4]CPT-Hex: 10-Hexyl-10Hphenothiazine (2,100 $\mathrm{mg}, 353 \mu \mathrm{mol})$ and paraformaldehyde (10.8 mg, $353 \mu \mathrm{mol}, 1$ eq.) were dissolved in degassed 1,2dichloroethane $(350 \mathrm{~mL})$. Trifluoroacetic acid $(17.5 \mathrm{~mL})$ was added, and the mixture was stirred at $80{ }^{\circ} \mathrm{C}$ for $5 \mathrm{~d}$ until no more starting material was observed by analytical gel permeation chromatography. After cooling to rt, the organic layer was washed with aq. sat. $\mathrm{NaHCO}_{3}(2 \times 100 \mathrm{~mL})$, dried over $\mathrm{Na}_{2} \mathrm{SO}_{4}$, and the solvent was removed under reduced pressure. Linear oligomers were removed by column chromatography $\left(\mathrm{SiO}_{2}\right.$, cyclohexane/EtOAc: $\left.20 / 1\right)$ to obtain the crude mixture containing different ring sizes and residues of linear oligomers ( $49 \mathrm{mg}, 52 \mu \mathrm{mol}, 44 \%$ ). The different ring sizes were separated by semipreparative gel permeation chromatography to obtain [3]CPT-Hex (16 mg, $18 \mu \mathrm{mol}, 15 \%$ ) and [4]CPT-Hex (4 mg, $1 \mu \mathrm{mol}, 4 \%$ ) as light yellow solids. Analytical data for [3]CPT-Hex: $R_{\mathrm{f}} \quad 0.49-0.60$ (cyclohexane/EtOAc: 20/1); ${ }^{1} \mathrm{H}$ NMR $\left(500 \mathrm{MHz}, \mathrm{CD}_{2} \mathrm{Cl}_{2}\right)$ : $\delta$ $7.03(\mathrm{dd}, J=8.3,2.0 \mathrm{~Hz}, 6 \mathrm{H}), 6.75(\mathrm{~d}, J=8.2 \mathrm{~Hz}, 6 \mathrm{H}), 6.68$ $(\mathrm{d}, J=2.0 \mathrm{~Hz}, 6 \mathrm{H}), 3.78(\mathrm{t}, J=7.1 \mathrm{~Hz}, 6 \mathrm{H}), 3.66(\mathrm{~s}, 6 \mathrm{H})$, 1.77-1.71 (m, $6 \mathrm{H}), 1.43-1.37(\mathrm{~m}, 6 \mathrm{H}), 1.31-1.26(\mathrm{~m}, 12 \mathrm{H})$, 0.88-0.84 (m, $9 \mathrm{H}) ;{ }^{13} \mathrm{C}$ NMR (126 MHz, $\left.\mathrm{CD}_{2} \mathrm{Cl}_{2}\right): \delta 144.2$, 136.1, 128.0, 127.7, 125.4, 115.4, 47.7, 40.4, 32.1, 27.4, 27.2, 23.2, 14.3; HRMS $\left(\mathrm{ESI}^{+}\right)$: $\mathrm{m} / z$ calcd. for $\mathrm{C}_{57} \mathrm{H}_{63} \mathrm{~N}_{3} \mathrm{~S}_{3} 885.4179$ $[\mathrm{M}]^{+}$, found 885.4179. Analytical data for [4]CPT-Hex: $R_{\mathrm{f}}$ 0.49-0.60 (cyclohexane/EtOAc: 20/1); ${ }^{1} \mathrm{H}$ NMR $(500 \mathrm{MHz}$, $\left.\mathrm{CD}_{2} \mathrm{Cl}_{2}\right): 86.96(\mathrm{dd}, J=8.3,2.0 \mathrm{~Hz}, 8 \mathrm{H}), 6.74(\mathrm{~d}, J=8.3 \mathrm{~Hz}, 8$ $\mathrm{H}), 6.74(\mathrm{~d}, J=2.1 \mathrm{~Hz}, 8 \mathrm{H}), 3.76(\mathrm{t}, J=7.3 \mathrm{~Hz}, 8 \mathrm{H}), 3.71(\mathrm{~s}, 8$ H), $1.78-1.72(\mathrm{~m}, 8 \mathrm{H}), 1.44-1.37(\mathrm{~m}, 8 \mathrm{H}), 1.32-1.27(\mathrm{~m}, 16 \mathrm{H})$, 
0.88-0.85 (m, $12 \mathrm{H}) ;{ }^{13} \mathrm{C}$ NMR (126 MHz, $\left.\mathrm{CDCl}_{3}\right): \delta 143.8$, 135.7, 128.0, 127.7, 124.9, 115.2, 47.7, 40.0, 31.9, 27.1, 27.0, 23.0, 14.1; HRMS (ESI ${ }^{+}$): $\mathrm{m} / z$ calcd. for $\mathrm{C}_{76} \mathrm{H}_{84} \mathrm{~N}_{4} \mathrm{~S}_{4} 1181.5672$ $[\mathrm{M}+\mathrm{H}]^{+}$, found 1181.5673 .

Synthesis of [3]CPT-Tol: $N$-(para-tolyl)phenothiazine (3, $300 \mathrm{mg}, 1.04 \mathrm{mmol}$ ) and paraformaldehyde (32.6 mg, $1.04 \mathrm{mmol}, 1$ eq.) were dissolved in degassed 1,2-dichloroethane $(200 \mathrm{~mL})$. Trifluoroacetic acid $(10 \mathrm{~mL})$ was added, and the mixture was stirred at $80{ }^{\circ} \mathrm{C}$ for $5 \mathrm{~d}$ until no more starting material was observed by analytical gel permeation chromatography. After cooling to rt, the organic layer was washed with aq. sat. $\mathrm{NaHCO}_{3}(3 \times 100 \mathrm{~mL})$, dried over $\mathrm{Na}_{2} \mathrm{SO}_{4}$, and the solvent was removed under reduced pressure. The residue was purified by column chromatography $\left(\mathrm{SiO}_{2}\right.$, cyclohexane/EtOAc: $50 / 1$ to $\left.10 / 1\right)$ and semipreparative gel permeation chromatography to obtain [3] CPT-Tol (95 mg, $105 \mu \mathrm{mol}, 30 \%$ ) as a colorless solid. $R_{\mathrm{f}}$ 0.29-0.43 (cyclohexane/EtOAc: 20/1); ${ }^{1} \mathrm{H}$ NMR (500 MHz, $\mathrm{CD}_{2} \mathrm{Cl}_{2}$ ): $\delta$ 7.42-7.39 (m, $\left.6 \mathrm{H}\right), 7.25-7.22(\mathrm{~m}, 6 \mathrm{H}), 6.74(\mathrm{dd}$, $J=8.4,2.1 \mathrm{~Hz}, 6 \mathrm{H}), 6.64(\mathrm{~d}, J=2.1 \mathrm{~Hz}, 6 \mathrm{H}), 6.16(\mathrm{~d}$, $J=8.2 \mathrm{~Hz}, 6 \mathrm{H}), 3.55(\mathrm{~s}, 6 \mathrm{H}), 2.45(\mathrm{~s}, 9 \mathrm{H}) ;{ }^{13} \mathrm{C}$ NMR $\left(126 \mathrm{MHz}, \mathrm{CD}_{2} \mathrm{Cl}_{2}\right): \delta 143.9,138.8,138.5,136.6,131.5$, 130.8, 127.4, 127.2, 121.1, 116.0, 40.1, 21.3; HRMS (ESI ${ }^{+}$): $\mathrm{m} / z$ calcd. for $\mathrm{C}_{60} \mathrm{H}_{45} \mathrm{~N}_{3} \mathrm{~S}_{3} 903.2770[\mathrm{M}]^{+}$, found 903.2769.

(1) Gutsche, C. D. Acc. Chem. Res. 1983, 16, 161.

(2) Gutsche, C. D. Calixarenes Revisited. Royal Society of Chemistry: Cambridge, 1998.

(3) Kumar, R.; Sharma, A.; Singh, H.; Suating, P.; Kim, H. S.; Sunwoo, K.; Shim, I.; Gibb, B. C.; Kim, J. S. Chem. Rev. 2019, 119, 9657.

(4) d'Ischia, M.; Napolitano, A.; Pezzella, A. Comprehensive Heterocyclic Chemistry III. Elsevier: Amsterdam, 2008, 353.

(5) Kohnke, F. H.; La Torre, G. L.; Parisi, M. F.; Menzer, S.; Williams, D. J. Tetrahedron Lett. 1996, 37, 4593.

(6) Musau, R. M.; Whiting, A. J. Chem. Soc., Perkin Trans. 1 1994, 2881.

(7) Lee, G.-A.; Wang, W.-C.; Shieh, M.; Kuo, T.-S. Chem. Commun. 2010, 46, 5009.

(8) Kim, I.; Ko, K. C.; Lee, W. R.; Cho, J.; Moon, J. H.; Moon, D.; Sharma, A.; Lee, J. Y.; Kim, J. S.; Kim, S. Org. Lett. 2017, 19, 5509.

(9) Chun, Y.; Singh, N. J.; Hwang, I.-C.; Lee, J. W.; Yu, S. U.; Kim, K. S. Nat. Commun. 2013, 4, 1797.

(10) Black, D.; Craig, D.; Kumar, N. Aust. J. Chem. 1996, 49, 311.

(11) Black, D. S.; Craig, D. C.; Kumar, N. Tetrahedron Lett. 1995, 36, 8075.

(12) Somphol, K.; Chen, R.; Bhadbhade, M.; Kumar, N.; Black, D. Synlett 2012, 24, 24.
(13) Yang, P.; Jian, Y.; Zhou, X.; Li, G.; Deng, T.; Shen, H.; Yang, Z.; Tian, Z. J. Org. Chem. 2016, 81, 2974.

(14) Li, G.; Zhao, L.; Yang, P.; Yang, Z.; Tian, Z.; Chen, Y.; Shen, H.; Hu, C. Anal. Chem. 2016, 88, 10751.

(15) Massie, S. P. Chem. Rev. 1954, 54, 797.

(16) Bodea, C.; Silberg, I. Adv. Heterocycl. Chem. 1968, 9, 321.

(17) Mietzsch, F. Angew. Chem. 1954, 66, 363.

(18) Jaszczyszyn, A.; Gąsiorowski, K.; Świątek, P.; Malinka, W.; Cieślik-Boczula, K.; Petrus, J.; Czarnik-Matusewicz, B. Pharmacol. Rep. 2012, 64, 16.

(19) Pummerer, R.; Gaßner, S. Ber. Dtsch. Chem. Ges. 1913, 46, 2310.

(20) Okafor, C. O. Dyes Pigm. 1985, 6, 405.

(21) Luo, J.-S.; Wan, Z.-Q.; Jia, C.-Y. Chin. Chem. Lett. 2016, 27, 1304.

(22) Okazaki, M.; Takeda, Y.; Data, P.; Pander, P.; Higginbotham, H.; Monkman, A. P.; Minakata, S. Chem. Sci. 2017, 8, 2677.

(23) Cho, N. S.; Park, J. H.; Lee, S. K.; Lee, J.; Shim, H. K.; Park, M. J.; Hwang, D. H.; Jung, B. J. Macromolecules 2006, 39, 177.

(24) Yang, C.-J.; Chang, Y. J.; Watanabe, M.; Hon, Y.-S.; Chow, T. J. J. Mater. Chem. 2012, 22, 4040.

(25) Esser, B. Org. Mater. 2019, 01, 063.

(26) Otteny, F.; Studer, G.; Kolek, M.; Bieker, P.; Winter, M.; Esser, B. ChemSusChem 2020, 13, 2232.

(27) Otteny, F.; Kolek, M.; Becking, J.; Winter, M.; Bieker, P.; Esser, B. Adv. Energy Mater. 2018, 8, 1802151.

(28) Acker, P.; Rzesny, L.; Marchiori, C. F. N.; Araujo, C. M.; Esser, B. Adv. Funct. Mater. 2019, 29, 1906436.

(29) Treat, N. J.; Sprafke, H.; Kramer, J. W.; Clark, P. G.; Barton, B. E.; Read de Alaniz, J.; Fors, B. P.; Hawker, C. J. J. Am. Chem. Soc. 2014, 136, 16096.

(30) Discekici, E. H.; Treat, N. J.; Poelma, S. O.; Mattson, K. M.; Hudson, Z. M.; Luo, Y.; Hawker, C. J.; de Alaniz, J. R. Chem. Commun. 2015, $51,11705$.

(31) Shibutani, S.; Kodo, T.; Takeda, M.; Nagao, K.; Tokunaga, N.; Sasaki, Y.; Ohmiya, H. J. Am. Chem. Soc. 2020, 142, 1211.

(32) Müller, T. J. J.; Franz, A. W.; Barkschat, C. S.; Sailer, M.; Meerholz, K.; Müller, D.; Colsmann, A.; Lemmer, U. Macromol. Symp. 2010, 287, 1.

(33) Rajakumar, P.; Kanagalatha, R. Tetrahedron Lett. 2007, 48, 8496.

(34) Memminger, K.; Oeser, T.; Müller, T. J. J. Org. Lett. 2008, 10, 2797.

(35) Mayer, L.; May, L.; Müller, T. J. J. Org. Chem. Front. 2020, 7, 1206.

(36) Li, C.; Chen, S.; Li, J.; Han, K.; Xu, M.; Hu, B.; Yu, Y.; Jia, X. Chem. Commun. 2011, 47, 11294.

(37) Brynn Hibbert, D.; Thordarson, P. Chem. Commun. 2016, 52, 12792.

(38) Thordarson, P. Chem. Soc. Rev. 2011, 40, 1305.

(39) Hahn, R.; Bohle, F.; Fang, W.; Walther, A.; Grimme, S.; Esser, B. J. Am. Chem. Soc. 2018, 140, 17932.

(40) Hahn, R.; Bohle, F.; Kotte, S.; Keller, T. J.; Jester, S.-S.; Hansen, A.; Grimme, S.; Esser, B. Chem. Sci. 2018, 9, 3477.

(41) www.supramolecular.org (accessed June 29, 2020). 